\title{
Field-dependence and form discrimination
}

\author{
GLEN M. VAUGHT AND JOHN ELLINGER
}

ALBION COLLEGE

Rod-and-Frame Test scores were correlated with performance in a tactile form discrimination task. It was found that the more field-independent the $S$, the higher the accuracy in the discrimination task. Of additional interest was the finding that the strongest correlation emerged between female RFT scores and the active touch condition.

Axelrod \& Cohen (1961) have reported a correlation of .78 between scores on a visual embedded-figures test and performance in a form discrimination task. In this study, each $S$ was blindfolded and felt the contours of a simple figure, which he then had to trace in a complex figure. While this study supports the idea that field-dependence cuts across sense modalities more studies need to be done in which oth _ _ ndicants of fielddependence are used in conjunction with other measures of form discrimination.

The present study sought to further investigate the relationship between field-dependence and form discrimination by using the Rod-and Frame Test (RFT) as an indicant of field-dependence. In addition, active and passive touch were investigated by using a modification of the tactile discrimination technique reported by Gibson (1962).

\section{Subjects}

The Ss were 20 male and 20 female introductory psychology students from Albion College, Albion, Michigan.

\section{Materials}

The form discrimination task consisted of six Masonite forms patterned after those employed by Gaydos (1956). Each form was reproduced in identical shape and size with black ink on white posterboard, and were numbered for purposes of identification.

A cardboard box was used in which the forms were presented to the Ss. Both sides were removed and one open side was draped with a black cloth so that when the box was turned up-side-down on a table the $S$ could put his hand into the box while the cloth shielded each stimulus from sight.

\section{Procedure}

The Rod-and-Frame Test was used as a measure of field-dependence.

In terms of the discrimination task, each condition in which a $\mathrm{S}$ performed was explained to him, but no knowledge of results nor any information as to the number of trials to be run was given. The six forms were randomly presented to each $\mathrm{S}$ until each form had been presented four times under each of two conditions, an active and a passive condition. Every $S$, therefore, ran a total of 48 trials with each trial lasting approximately $5 \mathrm{sec}$. The $S$ was required to place his dominant hand inside the box at which time the stimulus objects were randomly presented one at a time.

In the active condition, the $S$ was asked to put his hand inside the box palm down and to hold it above the table. A stimulus form was drawn from the container and laid on the table beneath the S's hand. On the command "go" the $S$ picked up the form, felt it, and then visually identified, by number, the figure on the chart that he thought was identical to the form in his hand. At the end of $5 \mathrm{sec}$. the $\mathrm{S}$ dropped the form on the command "drop" but was still allowed to respond if he had not done so already.

To perform in the passive condition, the $S$ was again asked to put his hand inside the boxbut with his palm up. Each form was then placed in the S's hand simultaneously with the "go" command and the trial then continued as described earlier.

Presentation of the stimulus for each trial was randomized by arbitrarily picking a form out of a box containing all six forms. The trials were balanced for each $S$ by presenting 12 trials under one condition, 24 under the other and 12 more under the first in an ABBA sequence. The Ss themselves were balanced by alternating the ABBA sequence with a BAAB sequence of trials for every other $S$. In this arrangement one $S$ would begin and end with 12 active trials in the ABBA sequence while the next $S$ would begin and end with 12 passive trials in a BAAB sequence. These precautions were taken to balance any learning by the Ss and to control for any influence one particular sequence might have on the other.

\section{Results and Discussion}

A correlation of $-.50(p<.01)$ was found between all Ss' scores on the RFT and the combined scores of active-passive form discrimination. It should be noted that the negative correlation was in the predicted direction, i.e., the more field-dependent the $S$, the fewer the errors in the form discrimination task. This finding supports the work of Axelrod and Cohen (1961) and provides additional evidence that field-dependence cuts across sense modalities.

Table 1 shows the correlations between RFT scores

Table 1. Product-Moment correlation Coefficients between RFT scores and form discrimination for all groups

\begin{tabular}{llll} 
& $\mathrm{N}$ & Active & Possive \\
\hline Males and females & 40 & $-.64^{* * *}$ & $-.35^{*}$ \\
Males & 20 & $-.41^{* *}$ & $-.33^{*}$ \\
Females & 20 & $-.80^{* * *}$ & $-.41^{* *}$ \\
\hline
\end{tabular}

$* p<.05$

${ }^{* *} p<.02$ (two-tailed test)

$* * * p<.001$ 
and accuracy of form discrimination for all groups. As can be seen, the strongest correlation emerged between RFT scores and active touch for females. This correlation was significantly higher $(p<.05)$ than the other correlations with the exception of the combined malefemale correlation with active touch.

The question of why a sex difference should exist between field-dependence and accuracy of form discrimination in the active touch condition remains largely unanswered at this time. The senior author has research underway in an attempt to account for this surprising finding.

\section{References}

Axelrod, S., \& Cohen, L. D. Senescence and embedded-figures performance in vision and touch. Percep. mot. Skills, 1961, 12 , 283-288.

Gaydos, H. Intersensory transfer in the discrimination for form. Amer. J. Psychol., 1956, 69, 107-110.

Gibson, J. J. Observations in active touch. Psych. Rev., 1962, $69,477-490$. 